\title{
O NOVO SINDICALISMO ENTRE O ANTIESTATISMO E A REGULAÇÃO DA ECONOMIA: qual perspectiva' ${ }^{1}$ (1978-1994)? THE NEW UNIONISM BETWEEN ANTI-STATISM AND THE
REGULATION OF THE ECONOMY: what perspective (1978-1994)?
}

\author{
Gustavo Antonio das Neves Bezerra²
}

\section{Resumo}

O Novo Sindicalismo surgiu criticando veementemente a presença do Estado na vida social brasileira. Mas será que isso teria feito desse movimento um precursor inadvertido do neoliberalismo? Essa insinuação ecoa no espaço público brasileiro vinda de distintas posições sociais. Face a tal problemática, o presente artigo interroga duplamente o período de ascensão dessa fração política. Em primeiro lugar, inquire qual seria a melhor maneira de definir o seu projeto societário primevo. A segunda interrogação remete ao modo como o Novo Sindicalismo teria reagido, na primeira metade da década de 1990, ao fato de que alguns de seus valores foram usados para justificar a erosão de dois dos principais alicerces de seu crescimento organizativo, a saber, o crescimento das ocupações assalariadas e a regulação estatal das relações entre capital e trabalho. Optou-se por uma pesquisa documental que aciona fontes primárias, com foco nas resoluções dos congressos da CUT e do PT. A hipótese é de que o Novo Sindicalismo teria amalgamado a sua exigência de face dupla - por uma cidadania política inovadora e pela manutenção dos dispositivos trabalhistas de cidadania social - através de uma visão de mundo mais classista do que propriamente ideológica.

Palavras chave: classes; novo sindicalismo; redemocratização; autonomia; direitos.

\begin{abstract}
The New Syndicalism emerged vehemently criticizing the presence of the State in Brazilian social life. But would this have made this movement an inadvertent precursor to neoliberalism? This hint echoes in the Brazilian public space from different social positions. In view of this problem, this article doubts the period of rise of this political faction. First, ask what would be the best way to define your primeval corporate project. The second question refers to the way in which the New Unionism would have reacted, in the first half of the 1990s, to the fact that some of its values were used to justify the erosion of two of the main foundations of its organizational growth, namely, growth wage occupations and state regulation of the
\end{abstract}

\footnotetext{
${ }^{1} \mathrm{O}$ artigo modifica e amplia um trecho de minha tese de Doutorado em Sociologia, defendida no IESP-UERJ em 2012 com o apoio da FAPERJ (bolsa nota 10).

2 Professor do Instituto de Planejamento Urbano e Regional da Universidade Federal do Rio de Janeiro (IPPURUFRJ).
} 
relationship between capital and labor. We opted for a documentary research that uses primary sources, focusing on the resolutions of the CUT and PT congresses. The hypothesis is that the New Unionism would have amalgamated its double-sided demand - for an innovative political citizenship and for the maintenance of the labor devices of social citizenship - through a more classist than properly ideological worldview.

Keywords: classes; new unionism; redemocratization; autonomy; rights.

\section{O NOVO SINDICALISMO ENTRE O ANTIESTATISMO E A REGULAÇÃO DA ECONOMIA: qual perspectiva (1978-1994)?}

O Novo Sindicalismo ${ }^{3}$, quando surgiu, criticou veementemente a presença do Estado na vida social brasileira. Mas será que isso teria feito dele e de suas florações organizacionais ulteriores, a Central Única dos Trabalhadores (CUT) e o Partido dos Trabalhadores (PT), desde sempre liberais ou precursores ingênuos do neoliberalismo? Essa insinuação ecoa no espaço público brasileiro desde a década de 1990, vinda de distintas posições sociais. À esquerda, alguns setores cobram o Novo Sindicalismo por seu suposto descompromisso com a herança trabalhista e até mesmo com os avanços da Constituição de 1988. Atribuem à díade CUT-PT uma tardia reconciliação com a era Vargas, cujo adiamento teria contribuído para a sedimentação do neoliberalismo no Estado e no debate público durante a primeira metade dos anos 1990. Do outro lado do espectro ideológico, em postura semelhante, mas valorativamente invertida, grupos empresariais e intelectuais convertidos ao projeto da globalização via mercado passaram a acusar CUT-PT de ter traído sua postura crítica ao Estado.

O sentido de uma vez mais pesquisar o Novo Sindicalismo vem das próprias batalhas recentes em torno da memória do processo de redemocratização no Brasil, que têm trazido interpretações tão novas quanto deformadoras sobre o tema. Isso significa, em todo caso, que as avaliações sobre o destino dessa floração sindical seguem rachando o debate público brasileiro. Seu discurso e sua atuação, primeiro como grupo oposicionista (à ditadura e à "Nova República") e mais tarde como grupo codirigente do aparelho de Estado (2003-2016), permanecem em tela de juízo no exercício de decifração de que país é este e, principalmente, na elucidação das pretensões e da potência da organização de sua classe trabalhadora.

Há um agravante que intensificou o interesse em retomar a investigação sobre o repertório dessa fração sindical: o fato de que o contexto simbólico neoliberal têm tido sucesso em recortar o debate

\footnotetext{
${ }^{3} \mathrm{O}$ artigo emprega grifos em itálico para conceitos e neologismos, aspas para categorias nativas empregadas pelo grupo estudado e grifos em negrito para enfatizar ideias contidas nos documentos originais aqui transcritos. Quando se fez relevante citar o ano original de algum texto citado mediante "apud", a menção veio entre colchetes.
} 
público a partir de seus próprios critérios, substituindo o tema das lutas de classe pelo da (in)utilidade do Estado. Na análise que faremos sobre a formação e a maturação do Novo Sindicalismo, aceitaremos parcialmente a pertinência desse debate acerca do Estado, mas restituindo a ele a grade cognitiva classista sobre a qual se baseavam as avaliações políticas do Novo Sindicalismo.

Para realçar o quão desconcertantes passariam ser os dilemas trazidos pela conversão repentina das classes dominantes brasileiras ao neoliberalismo após o fracasso do Plano Cruzado (cf. Sallum Júnior, 1999), lembre-se de que CUT e o Partido da Frente Liberal ${ }^{5}$ tiveram o mesmo posicionamento na Constituinte, em favor da liberdade sindical plena, enquanto, por outro lado, a central destoava do posicionamento de todas as demais entidades sindicais que se fizeram representar na Assembleia. Do lado patronal também houve disjunção entre as representações especificamente sindicais (como a da Confederação Nacional da Indústria), que defenderam a manutenção da organização corporativa de sindicato único prescrita pela velha CLT e, por outro lado, a postura liberalizante do Partido da Frente Liberal (cf. Almeida, 1996,181-185).

Á luz de tais questões, o artigo interroga duplamente o período de ascensão do Novo Sindicalismo. Em primeiro lugar, inquire qual seria a melhor maneira de definir o seu projeto societário primevo. A segunda interrogação remete ao modo como o Novo Sindicalismo teria reagido, na primeira metade da década de 1990, ao fato de que alguns de seus valores (participação, autonomia da sociedade civil, aversão ao corporativismo, desqualificação do passado enquanto "atraso" etc.) foram usados para justificar a erosão de dois dos principais alicerces de seu crescimento organizativo (e de sua fabulação societária acerca do futuro), a saber, a massificação das ocupações assalariadas e a regulação estatal das relações entre capital e trabalho.

Do ponto de vista analítico, o artigo parte do pressuposto de que o repertório da ação coletiva do movimento pode ser recortado em dois eixos. O primeiro deles estaria referido à cidadania política, marcado pela incorporação de valores inovadores e considerados subversivos pela ditadura civil-militar. Nesse eixo, situavam-se as reivindicações por autonomia sindical, o direito ao voto universal, a ideia de autogoverno e o direito irrestrito à greve. Um segundo eixo seria o da cidadania social, pelo qual se

\footnotetext{
${ }^{4}$ Como observou Foucault (2008), o traço característico do liberalismo como "arte de governar" é o deslocamento do tema da busca por justiça para o tema da busca pela "utilidade", sendo esse termo definido pelo cálculo ou o balanço entre ganhos e perdas implicados na ação política.

5 Atual partido "Democratas" (DEM). O Partido da Frente Liberal foi um racha "modernizador" da Arena, (partido de situação nos tempos da Ditadura) mais afeito a se desincompatibilizar formalmente da herança autoritária (Catanhede, 2001).

${ }^{6}$ Isso mostra que o PFL estava mais conectado com os novos modos de representação empresarial na cena pública apontados por Diniz e Boschi (1992) que com as tradicionais organizações patronais.
} 
adotava uma atitude corretiva $a^{7}$ em relação à herança varguista composta pela tríade trabalhismonacionalismo-desenvolvimentismo. Como é bem sabido, sequer a ditadura havia rompido com tal herança, tendo preferido dar a ela uma nova direção política, diminuindo o acento trabalhista ao passo em que acentuava, em versão autoritária, o nacionalismo e o desenvolvimentismo ${ }^{8}$. Analisando em conjunto as duas dimensões da cidadania aludidas, temos que CUT era apenas parcialmente antitética ao regime militar e à herança de 1930 em geral, característica que passara despercebida aos observadores durante os anos 1980.

Metodologicamente, optou-se por uma pesquisa documental que aciona fontes primárias, com foco nas resoluções dos dois congressos "pré-CUT" (1981 e 1983), de todos os congressos da entidade realizados na década de 1980 (1984, 1986, 1988) e dois CONCUTS da década seguinte (1991 e 1994). Também são mobilizadas as resoluções do PT da década de 1980, período em que o partido se assemelhava a um movimento social (voltado mais à produção e disseminação de valores do que à conquista de vitórias eleitorais) e comportava-se como uma espécie de extensão, na esfera política, da CUT (que, de forma simétrica e invertida, assemelhava-se a um partido, cf. CARDOSO, 2003).

Ainda que tais documentos tenham o limite de anular as acirradas disputas internas àquelas organizações, possuem a potencialidade de revelar-nos ao menos o tipo de relação que o chamado “campo majoritário" estabeleceu entre a cultura autonomista e o Estado Social desenvolvimentista" (modo pelo qual, doravante, chamar-se-á aqui o modo de encaminhamento da “questão social” vigente da década de 1930 à década de 1990).

O material de pesquisa foi completado por um levantamento de trabalhos acadêmicos que tematizaram a memória da ação sindical cutista, mas sem fazer deles os principais “informantes” da pesquisa, por considerarmos que o filtro interpretativo dos autores nos levaria às já bem documentadas polêmicas intrassindicais que caracterizaram a época, mas ao prejuízo de distanciarmo-nos do foco aqui

\footnotetext{
${ }^{7} \mathrm{O}$ artigo emprega grifos em itálico para conceitos e neologismos, aspas para categorias nativas empregadas pelo grupo estudado e grifos em negrito quando se pretende enfatizar palavras contidas nos documentos originais aqui transcritos. Quando se fez relevante citar o ano original de algum texto citado mediante “apud”, a menção veio entre colchetes.

${ }^{8}$ Sobre a tarefa corretiva a qual o regime militar se auto-atribuía em relação à Revolução de 1930, veja-se por exemplo esse depoimento: "Falo-vos eu, agora, em nome da Revolução de 1964 (...) Muitos de nós, os mais velhos, havíamos militado nas hostes revolucionárias de 1930. Ambos esses movimentos cívicos brotaram das mesmas fundas raízes brasileiras (...) E, em ambos, visava-se à criação de um Brasil maior, mais forte (...) A Revolução de 1930 encerrou todo o seu ciclo histórico, enfrentando vicissitudes várias e sofrendo naturais descaminhos, mas não faltou à sua destinação maior quando, na senda do desenvolvimento nacional, criou as bases iniciais da industrialização do país (...) É, a partir dessas bases, que o Movimento Revolucionário de 1964 está Construindo um Brasil Novo...(Geisel, 1977[1976]: 8990).

${ }^{9}$ Em Bezerra (2012), a ideia de um Estado social desenvolvimentista é um equivalente, em condições periféricas, do Estado Social conforme definição de Castel (1998). Em termos substantivos, o termo busca designar uma experiência de capitalismo reformado do pós-guerra (com base na relativa desmercantilização das relações de trabalho e na disseminação de bens e serviços públicos) adaptada para o caso brasileiro, a partir da incorporação das promessas de industrialização e de uma reforma agrária benigna às condições urbanas de assalariamento.
} 
escolhido: o do conteúdo do projeto societário cutista, que amalgamava a reivindicação por autonomia organizativa com a da expansão dos direitos trabalhistas. As influentes análises de Leôncio Martins Rodrigues (1991), Gianotti e Neto (1991) Iram Rodrigues (1997), Almeida (1996), Cardoso (2003) e Oliveira (2011) não mencionam conflitos significativos em torno do referido tema ${ }^{10}$. Por outro lado, é preciso notar que outros trabalhos já efetuaram análises voltadas à nuançar o "novo" no sindicalismo cutista, tendo influência sobre a presente pesquisa (por exemplo, Santana 1999 e Negro 1999)A hipótese é de que o Novo Sindicalismo teria amalgamado a sua exigência de face dupla - por uma cidadania política inovadora e pela manutenção e aprimoramento dos dispositivos trabalhistas de cidadania social - através de uma visão de mundo mais classista (vinculada, portanto, a um lugar social e seu grupo ocupante) do que propriamente ideológica (no sentido da escolha de uma metafísica doutrinal). Isso significa que a possibilidade de articulação daqueles enunciados aparentemente contraditórios, que a um só tempo negavam e afirmavam a obra da Revolução de 1930, estaria no projeto de colocar a direção política do país nas mãos de uma classe trabalhadora "autônoma", que conduziria os tradicionais dispositivos de enfrentamento da questão social num viés radicalmente democrático e participativo.

O final do artigo efetua um diálogo com um dos mais influentes e pioneiros estudiosos das relações entre Estado e sindicatos no Brasil, que é Luiz Werneck Vianna, autor de "Liberalismo e Sindicato no Brasil". O autor defende, há muitos anos, que as florações organizativas advindas do Novo Sindicalismo (CUT e PT) teriam sido plasmadas "pelo" e "para" os interesses de mercado, o que as tornaria supostamente avessas aos temas da "república" e da política (fenômeno do qual a votação contrária da bancada do PT à aprovação da Constituição de 1988 teria sido expressão máxima). O artigo busca, a partir do material empírico, ao menos nuançar tais juízos.

\section{Sujeitos e beneficiários do projeto social do novo sindicalismo}

Neste ano de 1981, a pressão de uma gravíssima recessão econômica, voltada para manter os interesses das poderosas empresas multinacionais ${ }^{11}$ e os grupos monopolistas nacionais, provoca crescente sofrimento da classe trabalhadora brasileira. Os trabalhadores têm sido historicamente marginalizados da vida política brasileira. Vivem sufocados por baixos salários, muitas vezes sem as mínimas condições de trabalho (...) as 183 entidades abaixo assinadas, reunidas em São Paulo no dia 21 de março de 1981, conclamam todos os trabalhadores brasileiros que vivem na cidade e no

\footnotetext{
${ }^{10}$ Oliveira (2011), por exemplo, considerou que as diferenças internas ao Novo Sindicalismo foram pouco significativas na primeira fase, quando o antagonismo se dava contra grupos sindicais "externos" (que mais tarde formariam a Confederação Geral dos Trabalhadores), tendo como objeto os problemas de organização sindical e não de programa social. Apenas depois da Constituição de 1988 e da subsequente reação neoliberal é que dentro do Novo Sindicalismo teria surgido um cisma mais significativo, referido ao grau de virulência desejável de suas reivindicações (sindicalismo "contratual" versus "de enfrentamento"). Em todo caso, O autor não documenta a ocorrência de polêmicas em torno da pertinência ou não do modelo legislado de Direito do Trabalho vigente no país.

${ }_{11}$ Todos os grifos em itálico nos documentos originais foram feitos pela autoria do artigo, exceto quando especificado.
} 
campo a participar da $1^{a}$. CONCLAT (...) realizando reuniões nas fábricas, fazendas, oficinas, lojas e escritórios, preparando assim uma grande CONCLAT! Pela estabilidade no emprego, contra o desemprego e a redução da jornada de trabalho com redução dos salários, contra a política recessiva do governo e dos patrões, pela unidade dos trabalhadores da cidade e do campo, pela reforma agrária... (CONFERÊNCIA NACIONAL DA CLASSE TRABALHADORA apud CENTRAL ÚNICA DOS TRABALHADORES, 2018 [1981]).

A conclamação para a "1 ${ }^{a}$ Conferência Nacional da Classe Trabalhadora”, de 1981, é considerada pela CUT como o seu documento preparatório mais ancestral. É um documento curto, cabível numa simples lauda. Sua concisão, entretanto, contribui ainda mais para ilustrar de modo explícito uma das principais construções simbólicas que acompanharia a futura central ao longo do tempo: a consagração de uma noção de classe social centrada numa categoria ampla de "trabalhador"12, formada por uma multiplicidade de experiências no mundo profissional e na vida social (agregadora de médicos a trabalhadores braçais), que estariam unificados pelo fato de viverem da renda gerada diretamente pelo trabalho (não importando qual o montante de renda auferida), em contraste àqueles dotados de posição patrimonial. Do mesmo modo, não interessava a origem da renda do trabalhador ${ }^{13}$ : funcionários públicos, assalariados de firmas privadas, trabalhadores por conta própria e profissionais liberais teriam interesses convergentes, sendo então impensável considerar que algum destes segmentos pudesse significar um obstáculo à elevação do padrão de vida do outro ${ }^{14}$.

Tal construção histórica do sujeito "classista" não se deu ao acaso. A classe trabalhadora nomeada pela CUT tinha parentesco lógico com a classe operária inglesa estudada por Thompson. Ambas as criações classistas estiveram embebidas numa dinâmica relacional, que lembra às ciências sociais a importância do pensamento dialético. O trabalhador do classismo cutista soube ser múltiplo porque reunia de modo direto todos os que seriam submetidos e marginalizados por um Estado historicamente autoritário e por um "grande" patronato atrelado àquele, praticante do autoritarismo intraempresa. A oposição de classe capaz de unificar as maiorias não acabaria aí. Embora ausente do panfleto fundador,

\footnotetext{
${ }^{12}$ Entre os sindicatos e associações profissionais, vindos de diversas partes do país, que assinaram o documento, estavam: vidreiros, economistas, alfaiates, eletricitários, operários fabris diversos, empregadas domésticas, bancários, jornalistas, trabalhadores em oficinas mecânicas, aeroviários, arquitetos, motoristas, desenhistas e projetistas, metroviários, joalheiros, padeiros, contabilistas, empregados no comércio, telecomunicações, mais de uma dezena de sindicatos rurais, entre outros.

${ }^{13}$ Ressalte-se, de qualquer forma, que não era a primeira vez que se evocava tal pluralidade como parte de uma mesma causa. Nos documentos do PCB, do período imediato pós-guerra, também havia o esforço por se constituir congregações análogas.

${ }^{14}$ Cabe não naturalizar muito tal construção. Lembre-se de que a ideia de que os setores laborais mais "organizados" se opõem aos "desorganizados" faria forte concorrência ao arrazoado classista inclusivo da CUT, a partir da segunda metade da década 1980. O contraste entre os dois arrazoados será objeto de detido exame ao longo do presente capítulo.
} 
o capital financeiro completaria nos documentos futuros a descrição do quadro do conluio político operado contra a maioria trabalhadora.

Mas o que uniria, afinal, esses agentes enquanto "inimigos" da classe trabalhadora? A análise documental nos traz a imagem de um Outro que é sempre um monopólio usurpador. A noção de monopólio aqui é fundamental para o entendimento da construção do inimigo classista operada pelo Novo Sindicalismo: é notável como a empresa nacional concorrencial (não-monopolista) nunca era explicitamente citada como adversária.

O Partido dos Trabalhadores chegaria a fazer uma empedernida defesa dos direitos de propriedade da "pequena burguesia" em documento estabelecido em seu quarto encontro nacional, situando aquele grupo como um aliado interno às "classes trabalhadoras" (Partido dos Trabalhadores, 1998 [1986], p. 253) ${ }^{15}$. Do mesmo modo, a apologia aos “de baixo" levaria a CUT a defender no seu congresso de fundação o direito ao voto de soldados e cabos (velha reivindicação comunista), ainda que esses fizessem parte de um segmento social que era seu antagonista na política.

A menção ao usurpador se dá, em regra, precedida pelo epíteto "grande" (grandes empresas, grande capital) ou remete a superlativos per se, como a menção às multinacionais. O grande era um adversário e o pequeno era um aliado em qualquer arena. Às cúpulas (sindicais, governamentais etc.) opunha-se, como valor, as bases, as organizações por locais de trabalho e as demandas por eleições diretas para todo e qualquer tipo de cargo. Por essa lógica, fazia-se também apelos à descentralização das atribuições governamentais, tratando-se a escala "local" como mais permeável ao clamor das bases. Tal oposição ao grande é importante pois, sobre a sua positividade oposta, a do pequeno, foram assentadas algumas definições futuras, dizendo respeito, por exemplo, à defesa da pequena propriedade rural.

Não se tratava, todavia, de uma rejeição pós-moderna às grandes dimensões típicas das estruturas sociais do fordismo. A crítica focalizava mais propriamente as questões da verticalidade e da hierarquia. A relação com as grandes dimensões era, de certo modo, dialética: aproveitar-se-ia as grandes dimensões (do sindicato, da central de lutas, do partido de classe) para promover uma democracia de massas horizontal, dentro e fora das relações de trabalho. Particularismos deveriam ser reconhecidos para agrupar "autenticamente", não para redundar em dinâmicas de isolamentos e compartimentações. Almejava-se ter a mesma morfologia agigantada dos inimigos (o grande Estado autoritário e o grande monopólio capitalista) de modo a sobrepujá-los na condução da vida social.

15 “...só é possível conquistar, para esse projeto comum, o apoio e a participação das grandes camadas da pequena burguesia rural e urbana, na luta pela radical transformação da sociedade rumo ao socialismo, no Brasil, se forem asseguradas a tais camadas condições reais do progresso social - sem ameaças a seus limitados meios de produção" (PARTIDO DOS TRABALHADORES, 1998 [1982], p. 253). 
A construção de um repertório de valores negativos, contra os quais os trabalhadores deveriam combater unificadamente, era um expediente essencial para a construção da identidade da classe e para constituir balizas de orientação da ação prática nas interações (quase sempre deliberadamente conflituosas) com o Estado e o patronato. Entre tais valores negativos, enumerava-se certo conjunto de epítetos, como: corporativismo, parasitismo, aparelhismo, patrimonialismo, paternalismo, burocratismo e cartorialismo.

Por fim, no que diz respeito à produção desse sujeito, é preciso fazer uma importante ressalva. Ainda que a noção ampliada e inclusiva de trabalhador esteja bem presente ao longo do tempo nas resoluções dos CONCUTs, ela é constantemente anulada por outra representação corriqueira: trata-se do fato do trabalhador ser reduzido, em diversos trechos dos mesmos documentos, à figura do assalariado e, principalmente, do assalariado formalizado e sindicalizado. Mais do que um descuido, a contradição parece apontar principalmente para um sintoma do contexto: a questão é que o assalariado formal sindicalizado parecia representar o futuro (enquanto base da universalização de conquistas sociais no tecido social brasileiro).

Por outro lado, a Central percebia tal contradição. Há um amplo leque de passagens nas quais ela se coloca a tarefa de estabelecer mais ativamente uma relação com o mundo externo ao salariado. Tratarse-ia, em tal reflexão, não de uma sobra externa à classe, mas de um resto tido como pré-sindical, enraizado no seio da classe trabalhadora. Haveria um campo popular não-sindicalizado ${ }^{16}$.

A existência desse resto, às vezes tido como "miserável", como "popular", como "desempregado" ou "marginalizado", era em larga medida agenciado para justificar a reinvenção do social (BEZERRA, 2012) que a CUT buscava operar, num momento em que a redemocratização deslegitimava a ideia de que os debates em torno do tema deveriam ser refreados em nome do combate à subversão. A própria atenção que a CUT dava às questões relativas ao trabalhador rural, figura alijada dos direitos trabalhistas até 1988, sugeria a intenção de estabelecer uma espécie de política compensatória ${ }^{17}$ no seio da própria classe trabalhadora. Uma das maiores demonstrações da preocupação da CUT com trabalhador rural (e de uma preocupação de cunho compensatório) foi o estabelecimento, no seu primeiro estatuto (1984), de que o vice-presidente da entidade seria sempre, necessariamente, de origem rural.

\footnotetext{
${ }^{16}$ Logo no Artigo 2 de seu estatuto, a CUT declarou que "Seu princípio é fundamental é a defesa intransigente dos direitos, reivindicações e interesses gerais ou particulares dos trabalhadores brasileiros bem como do povo explorado" (CENTRAL ÚNICA DOS TRABALHADORES, 2018 [1983]). Há, portanto, um enquadramento do "popular" que não se define pelas relações de trabalho, mas por uma forma abrangente de subordinação capaz de unificar trabalhadores e não-trabalhadores.

${ }^{17}$ No sentido de que a reorientação da política nacional deveria redundar num esforço maior de direcionamento de fundos públicos para os trabalhadores rurais que urbanos, ressalvando-se que a fonte maior destes fundos públicos deveria advir da expropriação ou tributação dos capitais e não das rendas de trabalhadores urbanos.
} 
A relação entre um whitecollar assalariado e um miserável não seria de oposição, mas de complementaridade política, na medida em que melhorariam de vida somente pela união contra o conjunto de subordinações operadas pelo Estado e pelo patronato monopolista. Tal arrazoado nivelador (mas não equalizador) pode ser enquadrado como parte de uma utopia devotada à construção de uma "sociedade de semelhantes" (CASTEL, 2005, p. 35), típica dos países de pacto social mais forte no contexto do pós-guerra. Num modelo social como esse, as pessoas encontrariam, a despeito de suas diferenças, na generalização do assalariamento coletivamente regulado as proteções sociais necessárias ao enfrentamento da condição de vendedores de força de trabalho. O socialismo, por esse prisma, afirmado pelo PT pela primeira vez seis anos depois de sua fundação, tendia a ser visto como o prolongamento e a intensificação desses dispositivos de autogoverno e de segurança social:

A democracia, no socialismo, deve ser entendida como a socialização dos meios de produção e também dos mecanismos de poder entre os trabalhadores. Isto significa ser favorável à liberdade de associação e organização, à livre expressão de ideias, à liberdade de culto, ao direito social à comunicação e à liberdade política, partidária e sindical. Aos trabalhadores caberá a tarefa de institucionalizar o Estado socialista através de um processo constituinte livre e democrático, que garanta os direitos e liberdade e que também assegure, dentro da nova legalidade, instrumentos e meios de defesa da sociedade (PARTIDO DOS TRABALHADORES, 1998 [1986], p. 256).

\section{A substância do projeto societário do novo sindicalismo}

“A legislação trabalhista no Brasil não exprime os interesses da classe trabalhadora...”. Assim começava a resolução "Direito do Trabalho", aprovada pela Conferência Nacional da Classe Trabalhadora de 1981 (CONCLAT). O texto segue:

\footnotetext{
...e pelo seu [da legislação trabalhista] caráter anti-democrático distorce e contraria os sonhos e conquistas do povo, mantendo e aprofundando a situação de insegurança e miséria que marginaliza milhões de trabalhadores, entravando a sua organização" (CONFERENNCIA NACIONAL DA CLASSE TRABALHADORA apud CENTRAL ÚNICA DOS TRABALHADORES, 2018 [1981]).
}

O que se pode interpretar desse toque de tímpano que abre a $1^{a}$ CONCLAT? Nada além do que a literatura acadêmica sempre mencionou: a vontade de recusar radicalmente o passado. Mas o que vem a seguir? "Os trabalhadores brasileiros exigem um Código Nacional de Trabalho elaborado através de amplas discussões pelos trabalhadores e seus sindicatos, como um passo fundamental para o estabelecimento de uma efetiva democracia" (IBIDEM). Onde está colocada a "inovação"? Sem dúvida na entrada em cena do sujeito político capaz de completar o Estado Social Desenvolvimentista no Brasil. Mas, para o debate 
público contemporâneo, o mais importante é notar o seguinte: não havia crítica formal ao passado, no que dizia respeito à necessidade de um Direito do Trabalho garantido pelo Estado ${ }^{18}$.

Como mais um sintoma de que a CONCLAT dedicou grande parte de seus esforços criativos a aprimorar uma herança, o que se segue aos trechos já transcritos é a reivindicação por um Código Nacional do Trabalho (CNT) que seria, na verdade, uma espécie de nova CLT (dessa vez produzida pela própria classe) contando com um amplo detalhamento de direitos e proteções sociais. Outra evidência de que a ruptura com a CLT seria muito seletiva está contida num trecho que vem pouco depois:

Que seja formado um grupo de trabalho, composto por representantes do movimento sindical e assessoramento da $\mathrm{OAB}$ e da Associação Nacional de Advogados Trabalhistas, para elaborar, em prazo curto, um código Nacional do Trabalho. Este grupo de trabalho deve (...) elaborar um Código Simples, que seja compreendido, discutido e assumido por todos os trabalhadores brasileiros e seja uma alternativa às investidas, golpes e pacotes, do governo e dos patrões. Enquanto não existir o CNT, lutar: pela revogação imediata do Titulo V da CLT; pleno cumprimento dos dispositivos da Consolidação das Leis do Trabalho de proteção aos trabalhadores e demais direitos trabalhistas (CONFERÊNCIA NACIONAL DA CLASSE TRABALHADORA apud CENTRAL ÚNICA DOS TRABALHADORES, 2018 [1981]).

O trecho possui ao menos duas menções claramente dirigidas ao "novo". A ideia de que o Código deveria ser simples representa uma crítica ao caráter burocrático atribuído à CLT, que, no imaginário cutista primevo, representaria um documento imposto e alheio à realidade das relações de trabalho no país. A legitimidade para descrever tais relações e para prescrever as regulações mais pertinentes estaria basicamente com as associações sindicais e seus consultores.

A afirmação mais contundente, contida ali, em direção à novidade diz respeito à supressão do “Título V” da CLT. Trata-se do trecho especificamente relativo à organização sindical. Observe-se, em síntese, que a CONCLAT não propôs a desestatização de qualquer direito, proteção ou benefício trabalhista, mas apenas o fim da tutela do Estado sobre os sindicatos, que era garantida por aquele dispositivo legal. As expectativas de incremento das negociações diretas (entendidas sempre como coletivas) entre patrões e trabalhadores não implicavam a defesa da extinção do modelo legislado de relações trabalhistas no Brasil, mas sim uma coexistência de regulações estatais e sindicais para qualquer situação.

Mas o documento de 1981 não se contentou em pleitear um novo repertório legislativo de direitos trabalhistas de modo abstrato. Mesmo querendo um código mais enxuto, o documento apresentou uma

\footnotetext{
18 A CUT viria se contrapor apenas ao dispositivo conhecido por "poder normativo" da Justiça do Trabalho, por considerar que a mesmo tendia a beneficiar os patrões nos dissídios coletivos.
} 
vasta e detalhada proposta de novos dispositivos de proteção social. Esses eram inovadores de duas maneiras alternativas: ou pelo ineditismo do que tomavam por objeto ou por ampliarem o espectro de cobertura de direitos pré-existentes. Tem-se, ao todo, 16 grandes itens vinculados especificamente ao tema do Direito do Trabalho ${ }^{19}$, contendo 80 sub-itens $^{20}$, voltados a subsidiar o futuro Código Nacional do Trabalho.

$\mathrm{Na}$ verdade, a maior parte dos dispositivos de proteção está em outro item, que é de longe o mais volumoso de todas as resoluções da CONCLAT de 1981. O documento relativo à "Saúde e Previdência Social" critica a política de saúde da ditadura militar, qualificada de "elitista e privatizante, [que] privilegia as grandes empresas médicas privadas, a indústria multinacional de medicamentos e equipamentos, em detrimento do trabalhador" (CONFERÊNCIA NACIONAL DA CLASSE TRABALHADORA apud CENTRAL ÚNICA DOS TRABALHADORES, 2018 [1981]).

O mais explícito indicador de que o programa cutista visava o aprofundamento do Estado Social desenvolvimentista está nas proposições voltadas a vincular permanentemente o trabalhador não só a um grupo socioprofissional, mas a um posto de trabalho específico dentro de uma firma. O emprego estável seria não apenas um caminho para vincular o trabalhador a um conjunto de direitos valorizáveis no presente, mas para atá-lo a uma categoria socioprofissional politicamente mobilizável. O congresso de fundação da CUT, em 1983, estabeleceria como bandeira de luta a "proibição do trabalho temporário, efetivando os trabalhadores que se encontram nessa situação" e o reconhecimento de que "todo trabalhador empregado seja considerado estável desde o primeiro dia de trabalho”. O mesmo congresso recusaria a extensão do FGTS para o trabalhador rural, por entender que o Fundo de Garantia era uma forma de flexibilizar o estatuto de jurídico da "estabilidade". Esse é que deveria ser recriado e estendido aos trabalhadores rurais.

O II Concut (1986) viria reafirmar a demanda pela "efetivação dos trabalhadores temporários e fim do trabalho temporário em todo território nacional”. Aparentemente, a dramática emergência pública do trabalhador boia-fria durante a redemocratização fazia com que a CUT tivesse reforçada a visão

\footnotetext{
${ }^{19}$ Direito ao Trabalho; Estabilidade no Emprego; Seguro-Desemprego; Fundo de Garantia por Tempo de Serviço; Direito de Greve; Convenção Coletiva de Trabalho; Salário Mínimo Real Unificado; Salário Profissional; Fiscalização do Trabalho (Higiene e Segurança do Trabalho); Jornada de Trabalho; Direitos da Mulher Trabalhadora; Trabalho do Menor; Direitos dos Trabalhadores Domésticos; Justiça do Trabalho.

${ }^{20}$ Entre tais dispositivos, alguns são caros a nossa caracterização do projeto societário cutista enquanto um projeto de regulação salarial: a demanda pela garantia de "que toda relação de trabalho gera um vínculo empregatício, gerando direitos e acessos aos benefícios sociais..." (primeira de todas as reivindicações); a defesa da extinção do contrato individual de trabalho; o reconhecimento jurídico da categoria "empregado doméstico"; "devolver e garantir as prerrogativas da Justiça do Trabalho para a solução dos conflitos que não possam ser solucionados pelas convenções coletivas de trabalho"; "criar um Código de Processo [judicial] do Trabalho com a participação dos sindicatos na sua elaboração".
} 
plenamente negativa dos trabalhos sem vínculo permanente ${ }^{21}$. Se perseguir o pleno emprego vitalício foi vivido como norma social em diferentes experiências europeias do pós-guerra, no Brasil essa figura foi assimilada como um ideal e o Novo Sindicalismo não representou exceção à regra.

\section{A CUT e a herança desenvolvimentista: expurgar o autoritarismo}

O sindicalismo reemergia na cena pública brasileira num contexto de grave crise econômica. Se a inflação e os baixos salários eram velhos conhecidos da experiência brasileira, dois novos eventos adicionavam-se para formar um cenário de grandes dificuldades: a interrupção de um processo de crescimento econômico vigoroso e relativamente contínuo; e, principalmente, o aparecimento do desemprego como fenômeno massificado. Os grupamentos sindicais favoráveis à formação da CUT (completada somente em 1983) promoviam uma reflexão acerca dessa crise econômica de novo tipo, de modo a interagir no debate nacional e a fortalecer o seu repertório de demandas transformadoras. E qual teria sido o diagnóstico cutista para a crise? Em 1981, a ainda CONCLAT respondeu do seguinte modo:

A crise econômica em que o governo mergulhou o país com a implantação de uma política nitidamente recessiva, de acordo com os interesses dos banqueiros e grandes empresas nacionais e estrangeiras, está levando a classe trabalhadora a uma situação de insegurança e de extremos sacrifícios. A pretexto de pagar a enorme divida externa que os governos autoritários vêm contraindo ao longo dos anos, os atuais governantes decidiram que a ordem é entregar a Bacia de Campos, os minérios de Carajás, as terras de Mato Grosso. Minas e Goiás; internacionalizar os sistemas financeiros, desnacionalizar o que resta da empresa privada nacional e privatizar empresas estatais mais rentáveis (...) Não temos, no país, um real planejamento econômico em todos os níveis CONFERÊNCIA NACIONAL DA CLASSE TRABALHADORA apud CENTRAL ÚNICA DOS TRABALHADORES, 2018 [1981]).

Nesse prisma, os efeitos deletérios do capitalismo deveriam ser mitigados pela ação reguladora de um Estado nacional condutor da economia, a partir do planejamento e do engajamento produtivo direto em certos setores na forma da empresa pública. Não há nesta questão, portanto, qualquer ruptura com o pensamento esquerdista anterior ao golpe de 1964. A CUT reafirmaria tais posições em diversos congressos, muitas vezes qualificando tais posições enquanto "anti-imperialistas".

\footnotetext{
${ }^{21}$ Repare-se que, antes da consolidação do Estado Social Desenvolvimentista no Brasil, a postura sindical não rara era oposta. Ou seja, considerava-se que era preciso lutar pela mobilidade ocupacional do trabalhador, quanto mais para o trabalhador qualificado. Por exemplo, os gráficos paulistas, em 1929, após experiência de greve, diriam que, entre as suas tarefas imediatas, estava: "Iniciar o trabalho de colocação dos operários que não quiseram voltar às antigas oficinas. Revoltados pela atitude reacionária dos ex-patrões durante o movimento que ora finda” (Apud CARONE,1984: 103).
} 
O FMI e a dívida externa eram repelidos por ameaçarem tal arranjo regulador, tirando a capacidade operatória do Estado nacional. O Estado autoritário seria, então, também um Estado “entreguista”, cabendo à classe trabalhadora estabelecer o potencial democrático e progressista da ação reguladora estatal. É bem verdade que os documentos da década de 1980 eram tímidos quanto a uma adesão mais explícita à noção de desenvolvimentismo. De qualquer forma, afirmava-se que o potencial do país para gerar empregos estava comprometido pela hegemonia do capital financeiro, que drenava recursos públicos para o pagamento de juros da dívida externa. Assim, propunha-se como uma das soluções para a crise econômica um:

\begin{abstract}
"programa de gasto de investimentos [sic] públicos, gerador de empregos, e não dependente de importações (...) Estímulo à produção de gêneros alimentícios e de primeira necessidade, congelamento de seus preços (...) reforma agrária ampla (...) Reforma tributária com incidência maior de impostos sobre ganhos de capital..." (CONFERENCIA NACIONAL DA CLASSE TRABALHADORA apud CENTRAL ÚNICA DOS TRABALHADORES, 2018 [1981]).
\end{abstract}

No II CONCUT, de 1986, a entidade incentiva uma "Campanha em Defesa das empresas Estatais, pela democratização da Ação do Estado e pela estatização dos serviços básicos" (CENTRAL ÚNICA DOS TRABALHADORES, 2018 [1986]). Por outro lado, observe-se que essa versão de Estado Social Desenvolvimentista era altamente crítica das práticas de fomento ao crescimento econômico do período autoritário. No início dos anos 1980, CUT e PT se posicionavam explicitamente contra a construção de grandes barragens, grandes projetos mineradores e projetos de colonização em regiões de fronteira econômica. Por exemplo, o congresso cutista de 1983 se colocava contra os projetos de colonização do Cerrado e da Amazônia “inclusive os de barragens e usinas hidrelétricas”, por entender que atendiam à expansão dos interesses privados das grandes corporações e não da classe trabalhadora ${ }^{22}$. Do mesmo modo, o congresso seguinte proporia a "nacionalização e a estatização da mineração" (CENTRAL ÚNICA DOS TRABALHADORES, 2018 [1984]) no país, como forma de reordenar as atividades laborais e a destinação dos recursos envolvidos na atividade.

Não havia, portanto, apologia de um crescimento econômico a todo custo. As variáveis qualitativas das práticas de "desenvolvimento" eram tão ou mais importantes que as quantitativas. Por fim, cabe registrar que as estratégias de regular politicamente as relações econômicas não coincidia com

\footnotetext{
${ }^{22}$ No congresso de 1988, a entidade denunciaria a falta de consulta às populações atingidas por barragem, mas cobraria basicamente o direito a um reassentamento em melhores condições, sem propriamente fazer críticas ao modelo energético e seus vínculos com o modelo de acumulação de capitais em marcha. Por outro lado, continua a ênfase na defesa de populações não-urbanas espoliadas como seringueiros, indígenas e ribeirinhos. A entidade também se colocou contra "a criação de colônias indígenas, a militarização da Amazônia e o Projeto Calha Norte" (CENTRAL ÚNICA DOS TRABALHADORES, 2018 [1988] p. 58).
} 
a intenção de transformar o país numa autarquia: na medida em que a integração internacional da economia brasileira aumentava de intensidade, os CONCUTS foram dando destaque à necessidade de uma atuação "internacionalista" dos trabalhadores e à expansão da regulação internacional sobre os fluxos de capital. A Central também manteve a orientação de qualificar as inovações tecnológicas como conquistas civilizacionais, que permitiriam a própria redução das jornadas de trabalho, desde que as decisões sobre as mesmas não fossem tomadas privadamente pelos empregadores.

\section{O novo sindicalismo era afim ao liberalismo econômico? Interpelação à Werneck Vianna ${ }^{23}$}

No primeiro momento, a produção acadêmica sobre o retorno da visibilidade pública da ação sindical destacou, com veemência, a vontade de inovação que impregnava a "voz" dos agentes estudados. Mais do que isso, buscou-se também chancelar a autenticidade de tal inovantismo, particularmente pela invenção acadêmica do termo Novo Sindicalismo. Para Perruso (2009), não houve somente chancela, mas um efetivo processo de codeterminação do fenômeno, considerando-se a proliferação de práticas de assessoramento acadêmico ao movimento sindical. Por meio dessas, os pesquisadores irradiavam um quadro favorável a que os sindicalistas se apresentassem, simbolicamente, como inovantistas plenos.

Porém, não tardaria a aparecer uma nova geração de estudos sobre o Novo Sindicalismo (em parte elaborados pela mesma leva de pesquisadores), que matizaria o grau de ruptura efetivamente alcançado $^{24}$. A presente pesquisa dialoga com tal exercício de matização, indicando que, de fato, o passado estava incrustado no programa societário do Novo Sindicalismo, na medida em que era sobre a conhecida tríade trabalhismo-nacionalismo-desenvolvimentismo que esses agentes fabulavam as suas futuras conquistas. Observando-se as continuidades e descontinuidades contidas nos documentos cutistas, é possível perceber que a alegada "fraude" do pretérito era atribuída não a um projeto regulador (de anteparo ao capitalismo) equivocado em si, mas a uma condução politicamente inautêntica do mesmo: somente a classe trabalhadora poderia utilizar o Estado e os sindicatos como efetivos dispositivos de regulação do capitalismo, reorientados a intensificar a capacidade auto-organizativa dessa mesma classe.

\footnotetext{
${ }^{23}$ Não é que Vianna acuse o Novo Sindicalismo e suas florações institucionais de terem um DNA privatista, mas seu enquadramento também não se volta a desfazer tal possível mal-entendido, deixando no ar uma certa ambiguidade em relação ao tema, quando fala do mercado como principal matriz explicativa das posições normativas dessa fração sindical. Por exemplo, em entrevista concedida em 2002, o autor diria que, na campanha presidencial daquele ano, "Lula trouxe o sindicalismo para o contexto republicano, embora seu partido tenha nascido fora desse contexto e, em certo sentido, contrário a ele. Aí está o sindicalismo como personagem da vida republicana, e não como simples força social do mercado" (VIANNA, 2006, p. 131).
}

24 Por exemplo Santana (1999). 
Assim, a sua adesão corretiva ao Estado Social desenvolvimentista ficava como ponto cego (e onipresente) de sua performance pública.

O acento procedimentalista de classe do Novo Sindicalismo e de seus aliados acadêmicos, que a alguns soou falta de projeto ${ }^{25}$, não derivava de uma suposta falta de reinvindicações substantivas, mas da adesão a um projeto histórico que não lhes cabia desfazer, pois jamais teria sido "autenticamente" conduzido. A CUT não era meramente experimentalista, espontaneísta (por oposição ao modo de ação "planejado" dos comunistas) ou basista: era simultaneamente um produto e um agente histórico da regulação trabalhista-nacionalista-desenvolvimentista construída décadas antes pelas interações conflituosas entre capital, trabalho e Estado no Brasil. O seu repertório de demandas por dispositivos regulatórios da acumulação de capital era mais do mesmo e seu diferencial residia na intensidade e na amplitude da regulação almejada, brandidas como provas da autenticidade de um processo liderado pela base.

De qualquer forma, vale destacar que, no esforço por consagrar um Estado Social Desenvolvimentista autêntico, os agentes do Novo Sindicalismo costumavam ansiar por uma inversão do veículo de regulação: substituir o Estado (de quem desconfiavam muito, inclusive da Justiça do Trabalho) pelo sindicato ${ }^{26}$, não só como ente regulador, mas também como ente gestor de fundos públicos ${ }^{27}$.

Feitas tais observações, faz sentido dialogar com a narrativa de Werneck Vianna em relação ao problema do americanismo nos meios sindicais. O reputado autor de "Liberalismo e Sindicato no Brasil" vem há muito se notabilizando no debate público brasileiro pela argumentação de que o sindicalismo surgido no $\mathrm{ABC}$ teria uma afinidade de origem com as práticas de desestatização da economia. Mobilizando Gramsci (mas ecoando também a Sérgio Buarque de Holanda) para opor analiticamente americanismo (mundo dos interesses econômicos) a iberismo (mundo organicista da nação e dos valores), Vianna vincula o Novo Sindicalismo à primeira matriz dado que "seu mundo é o do mercado, da fábrica, da negociação sobre o salário e as condições de trabalho, e não a república” (VIANNA, 2006, p. 57). O autor acrescenta que o encontro dessa matriz política com o tema do "nacional-popular" teria acontecido

\footnotetext{
${ }_{25}$ Para uma interpretação leninista crítica da alegada falta de programa especificamente do PT em suas origens, ver Montenegro (2009).

${ }^{26}$ No primeiro debate dos presidenciáveis de 1989, por exemplo, Lula declarou que o papel do Estado não era intervir na definição dos salários, mas permitir que os sindicatos negociassem livremente, inclusive para ganhar acima da inflação (ganho que o governo procurava impedir em diversos momentos da Nova República). Disponível no sítio do youtube em setembro de 2011.

${ }_{27}$ No item "questão nacional", o documento produzido pelo Movimento pelo PT apresentou a demanda do "controle popular dos fundos públicos" (Partido dos Trabalhadores, 1998 [1979], p. 60). O documento da CONCLAT, de 1981, afirmava que "o FGTS(...) constitui um fundo a ser gerido pelos trabalhadores".
} 
somente no final da década de 1990, por ocasião da aliança eleitoral desses setores com o trabalhismo de Brizola (IBIDEM, p. 65).

Segundo os achados da presente pesquisa, a ideia de americanismo para caracterizar o Novo Sindicalismo e, mais particularmente a extração vinda do $A B C$ paulista, só é pertinente desde que se observe que o americanismo deve ser distinguido, analiticamente, de uma postura privatista. Observe-se que Vianna toma por base Americanismo e Fordismo, texto escrito por Gramsci em 1934, que não aborda os efeitos do New Deal rooseveltiano ${ }^{28}$. Isso o leva passar ao largo da via americana de regulação social da acumulação capitalista, inventada nos anos 1930, centrada na contratação coletiva e no fortalecimento sindical incentivado pelo Estado ${ }^{29}$. O americanismo do Novo Sindicalismo só poderia ser entendido como afim à experiência dos EUA do período que superou a alternativa fordista "pura", que até então se destacava pela livre inciativa empresarial voluntarista ${ }^{30}$ e o anti-sindicalismo. O americanismo, quando aparecia nos discursos, basicamente remetia à demanda pelo retorno à "livre-negociação" salarial entre patrões e empregados, expediente proibido durante a ditadura (cf. ALMEIDA, 1996) e cuja adoção serviria para a conquista de reajustes superiores ao estipulado pela "política salarial" do governo ${ }^{31}$.

Pode-se dizer que a narrativa de Vianna aceita e reifica a autenticidade novidadeira daquele movimento, a despeito de não gostar de tal programa. Entretanto, fontes diversas revelam que não se acaba com uma tradição por voluntarismo. Em embates concretos, os velhos repertórios eram acionados ad nauseam pelo Novo Sindicalismo.

Cabe examinar mais de perto, para confrontar Vianna, o tipo de crítica que a CUT faria ao processo constituinte de 1986 a 1988. O exame dos documentos sugere uma contundente inconformidade, porém de tipo corretiva: afirmava-se que o processo de elaboração da nova carta iria ser comandado por forças conservadoras, que haviam proscrito uma autêntica Assembleia Nacional Constituinte em prol de um espúrio "Congresso com poderes constitucionais" (CENTRAL ÚNICA DOS TRABALHADORES, 2018, [1986]). Assim, a estratégia não deveria ser o boicote à constituinte,

\footnotetext{
${ }^{28} \mathrm{O}$ americanismo conhecido por Gramsci é o do voluntarismo empresarial, inspirado por Henry Ford. A nova disciplina do trabalho tinha uma faceta positiva, em termos de redução de jornada e aumentos salariais para os trabalhadores mais dóceis, o que só foi possível pela racionalização taylorista e a adoção de maquinário inovador que permitiam o aumento da mais-valia relativa sobre trabalhadores desqualificados. O New Deal introduziu, em contraste, as obrigações coletivas, a regulação social da economia, o fortalecimento dos sindicatos (o que Ford sempre temera e rechaçara) e a expansão da demanda a partir de gastos públicos.

${ }^{29}$ Note-se que o Direito do Trabalho americano, a despeito de não girar em torno do Estado, tem o mesmo objetivo de desmercantilizar as relações entre capital e trabalho e foi, desde o início, influente sobre o Direito do Trabalho internacional (cf. SILVA e HORN, 2008).

${ }^{30}$ Harvey (2004) demonstrou que o fordismo só se tornou efetivamente o "modo social total de vida" preconizado por Gramsci quando, contrariando o próprio liberal Henry Ford, o ajuste entre oferta e demanda de massas (com elevação da produtividade e disciplina no trabalho e no consumo) passou a ser organizado pelo Estado e pelos sindicatos.

31 As "leis salariais" vigoraram e 1965 a meados dos anos 1980. Tratava-se de regras de recomposição salarial perante a inflação, que substituíam (pela proibição) as livres negociações entre patrões e empregados.
} 
mas criar ampla mobilização social no sentido de obter uma carta moldada aos interesses da classe trabalhadora. No congresso seguinte (1988), a entidade abusaria dos adjetivos negativos para descrever o documento saído da constituinte, em clara postura isolacionista. No todo, entretanto, a postura era ambígua, pois valorizava as "vitórias" que a mobilização popular teria conquistado. O casuísmo institucional acabaria se transformando no programa da entidade em relação à nova carta: “... não [devemos] reconhecer nenhuma legitimidade [da Constituição] para cercear a democracia (...) [devemos] garantir a efetivação dos direitos inscritos na nova Constituição e, ao mesmo tempo, dentro e fora dos marcos institucionais, intensificar a mobilização no sentido de conquistar as reivindicações negadas pela maioria conservadora (CENTRAL ÚNICA DOS TRABALHADORES, 1988).

Portanto, em que pese todas as ambiguidades, é difícil sustentar que o Novo Sindicalismo estivesse de costas para a República. Além das questões socioeconômicas, essa base social perseguia, pelo próprio tipo de confronto que estabelecia contra o Estado, os direitos de cidadania política, em particular o direito de formar e votar na sua própria diretoria sindical. Aquilo que era construído como o grande drama da nação - a cassação do voto - era o mesmo drama vivido pelos sindicatos em seu próprio terreno. Nesse sentido, é expressivo que o primeiro item da "Plataforma Política" do Movimento pelo PT tenha se chamado "liberdades democráticas" e que, junto às bandeiras da liberdade de organização sindical, reivindicassem o "fim imediato das eleições indiretas", a "Anistia Ampla, Geral e Irrestrita", e a "Convocação de uma Assembleia Nacional Constituinte, livre, democrática e Soberana" (PARTIDO DOS TRABALHADORES, 1998 [1979], pp. 58-59)32. Sua cultura de ativismo autonomista era o grande tema da refundação da República, segundo o Novo Sindicalismo.

Oliveira (2011) chegou à mesma conclusão quando confrontou as análises de Maria Hermínia Tavares de Almeida e Leôncio Martins Rodrigues que, em consonância a Vianna, consideram o Novo Sindicalismo uma variante da via americana do sindicalismo liberal radical:

Não há nenhum registro de que naquele campo de experiência em formação teria se configurado uma visão liberal, como doutrina, nos termos em que se tornou predominante no caso americano (...) o esforço principal daquela experiência em formação (não obstante suas diferenças internas) era do constituir o sindicato como um espaço de representação e participação (OLIVEIRA, op. Cit, p. 355).

Cenas do documentário “Linha de Montagem” (TAPAJÓS, 2007 [1982]), que cobriu as grandes greves de 79 e 80, ilustram como a conjuntura induzia a que a valorização desses direitos políticos (como o direito a uma "diretoria livre") se sobrepusesse à questão salarial. Pode-se ver ali que os grandes

\footnotetext{
${ }^{32} \mathrm{~A}$ reivindicação por uma Assembleia Nacional Constituinte "livre e soberana" também apareceu no primeiro documento pré-CUT, de 1981.
} 
momentos de comoção coletiva são os da luta contra a destituição legal da diretoria do sindicato, da prisão e da posterior libertação de seus diretores.

\section{CONSIDERAÇÕES FINAIS}

Nos derradeiros anos da ditadura militar, o contexto que amalgamava funcionalmente autoritarismo político e aviltamento das condições sociais influenciou a emergência de um movimento sindical antitético a essas duas condições, que logrou constituir um repertório de ação de dupla ênfase: por um lado, uma cidadania política inovadora (que enfatizava autonomia e auto-organização) e, por outro, uma cidadania socioeconômica com base no reforço e na extensão de proteções sociais formalmente vigentes, porém, até então frágeis e seletivamente asseguradas (sempre sujeitas ao cancelamento pelo arbítrio estatal-empresarial). A possível contradição entre o novo e a tradição era, todavia, "resolvida" pela ênfase no discurso classista, que afirmava a necessidade de que os trabalhadores assalariados (que compunham 75\% da PEA urbana em 1977, cf. IBGE, 2003 ${ }^{33}$ ) conduzissem o país politicamente, a partir de suas organizações sindicais, movimentos sociais e partidos políticos. A novidade da classe autônoma realizaria e ultrapassaria as "falsas" (mas não indesejáveis) promessas do Estado Social Desenvolvimentista (marcado pela tríade regulatória trabalhismo-nacionalismo-desenvolvimentismo).

A preferência pela regulação efetuada diretamente pelas bases sindicais sobre (mas não "contra”) a regulação estatal foi lida por alguns intérpretes como um traço liberal. As evidências que encontramos não confirmam tal ideia. O basismo dessa vertente sindical de fato justifica a alusão a um perfil "americanista", mas desde que se entenda por tal termo apenas um deslocamento em direção à sociedade civil como foco da regulação social da economia e não a recusa a essa. O que ganhava força era a contratação coletiva do trabalho, por ser considerada um dos principais alicerces de uma democracia participativa (em que pese todas as contradições dessa perspectiva com a da apologia do socialismo, já apontadas por Oliveira, 2011).

Voltando ao problema posto no início do artigo, referido à sui-generis convergência entre Novo Sindicalismo e PFL no posicionamento favorável à liberdade sindical na Constituinte, a pesquisa sugere que as razões eram substancialmente opostas. Enquanto os representantes do Novo Sindicalismo tinham aí uma frente de politização da questão sindical contra as amarras do Estado autoritário, os predecessores do DEM contribuíam para reinventar a estratégia das classes dominantes no Brasil, que desde então esvaziava a grade cognitiva da luta de classes em favor de um discurso supostamente técnico sobre o Estado, pelo qual jogariam o autoritarismo e as proteções socioeconômicas coletivas na vala comum do

\footnotetext{
${ }^{33}$ Em 1984, o percentual chegaria a 78\%, para depois cair nas décadas neoliberais.
} 
“intervencionismo”. É preciso avaliar, em pesquisas futuras, se o Novo Sindicalismo mordeu a isca, convertendo-se apenas no inverso simétrico de seus adversários, passando a defender a ação estatal e o propalado "novo desenvolvimentismo" de forma acrítica, além de ter perdido sua visão original de classe ancorada na distinção entre aqueles que vivem de seu trabalho contra aqueles que vivem de rendas de capital.

\section{REFERÊNCIAS}

ALMEIDA, Maria Hermínia Tavares de. Crise Econômica e Interesses Organizados. São Paulo: Editora Universidade de São Paulo. 1996.

BEZERRA, Gustavo. O jogo pós-salarial: questão social, redemocratização e capitalismo móvel no Brasil. 2012. 294 folhas. Tese (doutorado em sociologia), Universidade do Estado do Rio de Janeiro, Rio de Janeiro, $2012 . \quad$ Disponível em: http://bdtd.ibict.br/vufind/Record/UERJ 9c025cb11ec7f64c2c7e13569ac35b3d

BOLTANSKI, Luc; CHIAPELLO, Eve. O Novo Espírito do Capitalismo. São Paulo: Martins Fontes. 2009.

BOURDIEU, Pierre. Razões Práticas: sobre a teoria da ação. Campinas: Papirus Editora. 1997.

CASTEL, Robert. As Metamorfoses da Questão Social: Petrópolis, Editora Vozes, 4.a edição. 1998. . A Insegurança Social. Petrópolis: Editora Vozes. 2005.

CARDOSO, Adalberto Moreira. A Década Neoliberal. São Paulo: Boitempo Editorial. 2003.

CARDOSO, Fernando Henrique. Por um Brasil Solidário (discurso de presidencial de posse). Página eletrônica. 1999. Disponível em: http://ftp.unb.br/pub/UNB/ipr/rel/discpr/1999/2869.pdf.

CARONE, Edgard. Movimento Operário no Brasil (1964-1984). Volume III. São Paulo: Difel, 1984 CATANHÊDE, Eliane. O PFL. São Paulo, Publifolha. 2001.

CENTRAL ÚNICA DOS TRABALHADORES. Congressos. Página eletrônica. 2018. Disponível em: https://www.cut.org.br/arquivos/congressos. Acesso em janeiro de 2018.

DIEESE. Boletim do DIEESE. S.L.: Ano 1, maio, 1982.

Boletim do DIEESE. S.L.: Ano II, junho. 1983

DINIZ, Eli; BOSCHI, Renato. Lideranças Empresariais e Problemas da Estratégia Liberal no Brasil. 1992. Página eletrônica. Disponível em: http://www.anpocs.org.br/portal/publicacoes/rbcs_00_23/rbcs23_08.htm.

Acesso em 07/2012. 
FOUCAULT, Michel. Nascimento da Biopolítica. São Paulo: Martins Fontes. 2008.

GALVÃO, Andreia. Do coletivo ao setor, do setor à empresa. A trajetoria do Novo sindicalismo Metalurgico nos anos 90. In: In: RODRIGUES, Iram J. (Org.). O Novo Sindicalismo - Vinte anos depois. Petrópolis, Vozes/Educ/Unitrabalho, 1999.

GEISEL, Ernesto. Discursos (vol. III). S.L.: Assessoria de Imprensa da Presidência da República. 1977.

GIANNOTTI, Vito. NETO, Sebastião Lopes. Cut Por Dentro e por Fora. Petrópolis: Vozes, 1991.

GOMES, Angela Castro. A Invenção do Trabalhismo. São Paulo: Vértice, 1988.

HARVEY, David. Condição Pós-Moderna. São Paulo: Edições Loyola, 2004.

IBGE. Estatísticas do Século XX. Rio de Janeiro, IBGE. 2003.

MONTENEGRO, Darlan. O Avesso do Príncipe: política e organização nas origens do Partido dos Trabalhadores. 2009. 226 folhas. Tese (doutorado em ciência política), Universidade do Estado do Rio de Janeiro, Rio de Janeiro, 2009.

NEGRO, Antonio Luigi. Nas origens do Novo Sindicalismo: o maio de 59, 68 e 78 na indústria automobilística. IN: RODRIGUES, iram j. (org.). O Novo Sindicalismo. Vinte anos depois. Petrópolis: Vozes/Educ/Unitrabalho. pp. 9-31, 1999.

OLIVEIRA, Roberto Véras. Sindicalismo e Democracia no Brasil: do novo sindicalismo ao sindicato cidadão. São Paulo: Annablume, FAPESP, 2011.

PARTIDO DOS TRABALHADORES. Resoluções de Encontros e Congressos. São Paulo: Editora Fundação Perseu Abramo, 1998.

PERRUSO, Marco Antonio. Em Busca do "Novo": intelectuais brasileiros e movimentos populares nos anos 1970/80. São Paulo: Annablume. 2009.

RODRIGUES, Leôncio Martins. As Transformações da Sociedade Contemporânea e o Futuro do Sindicalismo. In REIS VELLOSO, J.P e RODRIGUES, L.M, O Futuro do Sindicalismo. São Paulo: Nobel. 1992.

RODRIGUES, Iram Jácome. Sindicalismo e Política: a Trajetória da CUT. São Paulo: Scritta, 1997.

SALLUM JUNIOR, Brasílio. O Brasil sob Cardoso: neoliberalismo e desenvolvimentismo. In: Tempo Social - Revista de Sociologia da USP. São Paulo: v. 11, n. 2, 1999.

SANTANA, Marco Aurélio. Política e História em Disputa: O 'Novo Sindicalismo' e a Ideia da Ruptura com o Passado. In: RODRIGUES, iram j. (org.). O Novo Sindicalismo. Vinte anos depois. Petrópolis: Vozes/Educ/Unitrabalho. pp. 9-31, 1999.

SANTOS, Wanderley Guilherme. Décadas de Espanto e uma Apologia Democrática. Rio de Janeiro: Rocco, 1998. 
SIMÕES, Enilson. Sem título. In: "Projetos Estratégicos Alternativos para o Brasil: conferência do Rio de Janeiro". Rio de Janeiro: FASE-FUJB. 1995.

SILVA, Sayonara Grilo Coutinho Leopardo da; HORN, Carlos Henrique. O princípio da proteção e a regulação não-mercantil do mercado e das relações de trabalho. Revista de Direito do Trabalho, s.l., n. 132, 2008, pp. 184-20.

TAPAJÓS, Renato. Linha de Montagem. Audiovisual. 2007. Disponível em: https://www.youtube.com/watch?v=3MuoLdrapBE

THOMPSON, Edward Palmer. A Formação da Classe Operária Inglesa (3 volumes). São Paulo: Paz e Terra. 2004.

VEJA. Sem título. S.l. 31/05/1978. Disponível em: http://veja.abril.com.br/acervodigital/. Acesso em junho de 2012.

VIANNA, Luiz Werneck. Liberalismo e sindicato no Brasil. Rio de Janeiro: Paz e Terra. 1976.

2006.

Esquerda Brasileira e Tradição Republicana. Rio de Janeiro, Revan,

WEINSTEIN, Barbara. For Social Peace in Brazil: the Industrialism and the Remaking of the Working Class in São Paulo. Chapel Hill/London: The University of North Carolina Press, 1986. 